\title{
Role of Nurses in the Management of Common Gynecological Diseases: Recent Advances
}

\author{
Hardeep Singh Tuli* \\ Department of Biotechnology, Maharishi Markandeshwar (Deemed to be University), Mullana-Ambala 133 207, Haryana,
} India

*Corresponding author: Hardeep Singh Tuli, hardeep.biotech@gmail.com

\begin{abstract}
In recent years the role of the specialist nurse with respect to gynecology and women's health has gained significant importance. The advancement in the nursing practice has provided an insight to interact with patients to explore their history. Such hysteroscopy procedures may not only give a better feel to the patient but also explore the need for doctor treatment. The review updates about the ongoing advances in the field of nursing science to upgrade the life of patients with gynecological diseases. Evidence has suggested the promising role of nurses to motivate patients with improved health after the treatment. The present review will cover the various health issues of women including menstrual dysfunction, fertility, and management of pregnancy's termination, uro-gynecological issues, and gyne-oncology, etc. The role of nurses during the above health issue will be discussed via various procedures. Therefore, the present review will conclude the significant importance of nurses in women's health issues to sustain happiness and to strengthen the need to bring advances in the curriculum of nurses to full fill the requirement of medical staff.
\end{abstract}

Keywords: Gynecology; Menstrual problems; Papillomavirus; Fertility issues; Abortion; Cancer

Publication date: September 2021; Online publication: September 30, 2021

\section{Introduction}

Nurses are playing a key role to improve women's gynecological issues via medical counseling. In the last decade, the requirement for trained nursing staff has increased significantly. Nurses curriculum has also been revised a lot to empower them with advanced medical practitioner skills ${ }^{[1-4]}$. Such trained practitioner nurses may have expertise (Figure 1.) in a diverse range of areas like obstetrics, gynecology, urogynecology, gynecologic oncology, and infertility, etc. Therefore, such practitioner nurses may be appointed at rural primary health care centers to help poor peoples. It has been estimated that out of 44 million health care staff, 21 million corresponds to nurses and midwives ${ }^{[5-7]}$. Therefore, the rate of nurse's occupation is much higher which suggests promising carrier perspective of nurses to full fill the need of patient's healthcare. Recent researches have shown that a woman faces more health issues and frequent visit to hospitals in comparison to men. It has been estimated that all women may face minor /or major gynecological issues in their life. Mostly, the cases are minor and treatable with personal hygienic and medical counseling. However, some of the cases may turn into severe complications and required major surgeries and lifelong medical consultancy.

Therefore, a regular visit to medical centers and proper nursing care can prevent several gynecological health issues. For instance, a nurse practitioner starts a telephonic conversation with women patients with gynecological problems and instructs them if there is an emergency to visit the hospital or not ${ }^{[8-10]}$. The educational skills of nurses ensure to retrieve the necessary information via hysteroscopy investigation to analyze the required test as well as disease diagnosis. Nurses apply a set of necessary questioners to know 
sensitive issues including sexual history, contraception, and pregnancy, etc. Nurses are also trained for physical examinations of women patients with gynecological issues ${ }^{[11,12]}$. Therefore, such gynecological specialist nurses may help women patients a lot to omit their clinical symptoms. The present review is describing the advancement in the nursing profession to combat women's gynecological issues to ensure high-quality care.

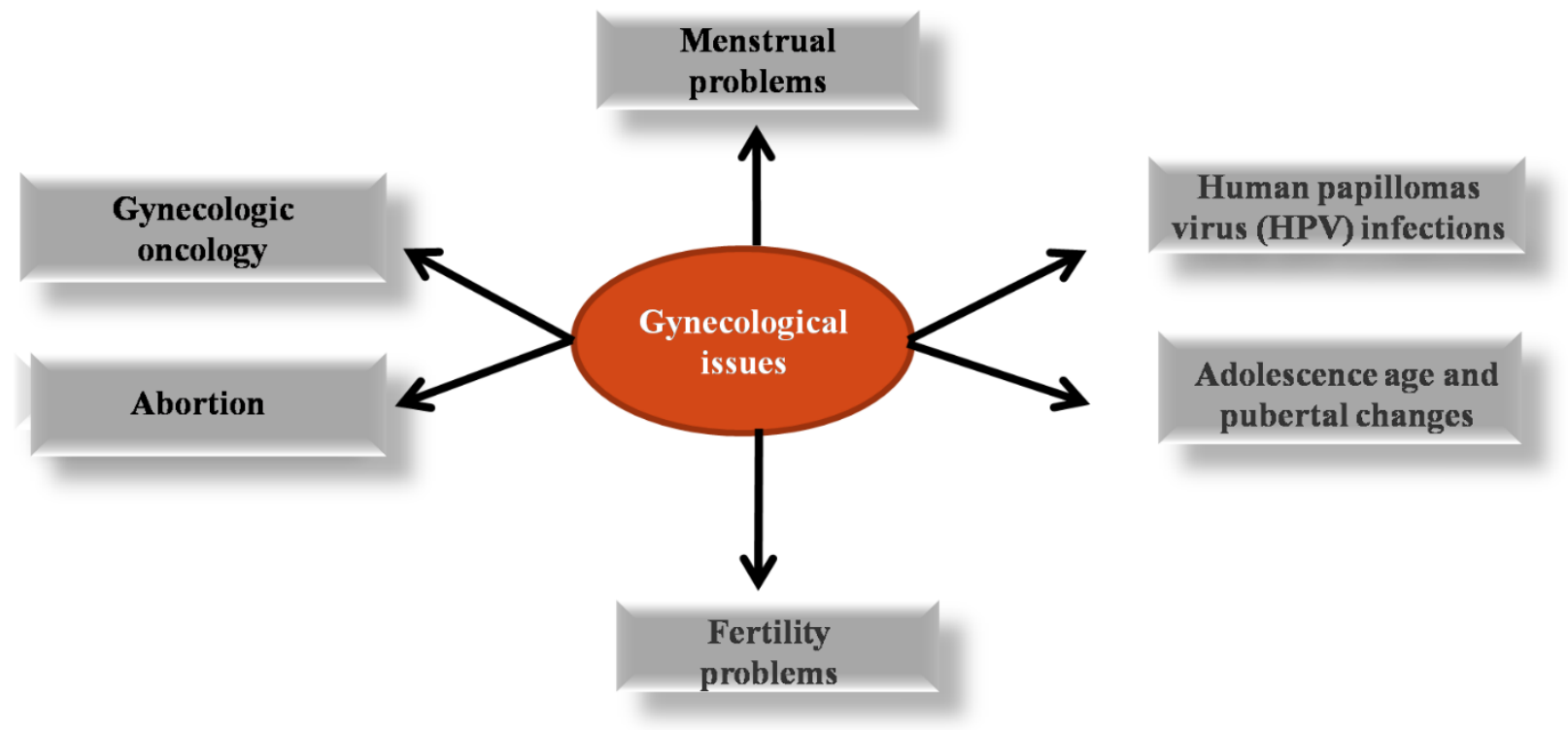

Figure 1. Immense potential of nurses to deliver in a diverse range of gynecological problems of women.

\section{Gynecological issues in women}

\subsection{Menstrual problems}

Problems in the menstrual cycle are considered to be one of the most common causes of women patients' consultancy ${ }^{[13,14]}$. Studies described 1 out of 20 women in the age group of 30 to 49 visits medical centers each year due to menstrual cycle issues. Several times it has been seen that women consider heavy menstrual bleeding a normal process. Even they feel embarrassed to discuss such issues socially and tried to manage themselves. During the last decade, this area of women's health has researched a lot and come up with numerous clinical improvements ${ }^{[15,16]}$. It has been observed that menstrual heavy bleeding issues disturb women's social and emotional relationships. Unregulated release of hormones is found to be associated with heavy bleeding issues in younger age women ${ }^{[17,18]}$. However, in many cases, fibroids and Polyps of endometrial may also be seen during the hysterectomy of patients. Such pathological issues can only be identified via clinical examinations ${ }^{[19,20]}$. A woman with a history of heavy menstrual bleeding undergoes physical examination for speculum and abdominal to explore the size of uterus and fibroids. In addition, patients are examined for total blood count and clotting disorders. If patients found with significant menstrual bleeding symptoms, then pharmacological treatment is initiated for up to 3-months. Several drugs including levonorgestrel, Tranexamic acid, mefenamic acid, may be considered to prevent heavy bleeding ${ }^{[21-23]}$.

\subsection{Human papillomavirus (HPV) infections to women's}

HPV is responsible to cause skin warts in the cervix region and known to initiate cervical cancer in women. Out of 100 different types of papillomavirus, 40 are known to infect genital areas ${ }^{[24-26]}$. They are further divvied into two categories including low risk and high risk of cancer-causing virus. HPV- 16 as well HPV 18 is found to be a common cause of cervical cancer. The HPV infection leads to cervical intraepithelial neoplasia or the formation of precancerous outgrowth ${ }^{[27-30]}$. In $70 \%$ of the cases of women 
with HPV viral infections had sexual intercourse history. However, mostly, this infection is self-healed by the body's immune system. Women are further encouraged to regular checkup and colposcopy of their cervix from nurse colposcopist ${ }^{[31-34]}$. Special training courses are being offered to train skilled nurses for such colposcopy testing of women. Such colposcopic examinations provide insights to detect the severity of diseases and infections. In most countries, colposcopy is highly recommended before starting any therapy, and colposcopists instructed to critically examined cytology and histology for accurate diagnosis ${ }^{[35]}$.

\subsection{Adolescence age and pubertal changes}

Adolescence age is considered to be very important in women's life due to the progression of biological as well social maturity ${ }^{[36-39]}$. Nurses are provided training to help girls of adolescent age to tackle menstrual and congenital problems. During the pubertal time period, a young person develops the growth of secondary sex organs. Prominent growth of breasts is generally seen in young girls during puberty followed by development in other regions. It usually takes 18 months to complete the growth of secondary sex organs

${ }^{[40]}$. Recent studies demonstrated that puberty age is decreasing due to unhealthy lifestyles ${ }^{[41-43]}$. In many countries, the puberty age is decreased and started from 12.3 years instead of 15 years. Experience nurses ask a set of questions to the young girl and try to explore the reason for their visit to the medical center. Nurses are very well aware of the anatomy of adolescent girls and the ongoing changes in their reproductive parts ${ }^{[44,45]}$. For instance, the development changes of the vulva at the time of puberty are noticeable. Experience nurses always take such changes in mind before reaching any diagnostic decision. During medical examination young girls are found to be unfamiliar with the nomenclature of female anatomy and the changes of puberty stage.

\subsection{Fertility problems}

After one year of marriage women generally try to have a child in their life. In last few decades, it has been observed that couple avoids having parenthood before 35 years. Such delaying in family planning may affect female fertility ${ }^{[46-49]}$. If a couple not able to have a child even after having unprotected sex for more than a year should visit a medical center. There has been a diverse range of infertility reasons including ovulation disorders, fallopian tube, and uterine disorders ${ }^{[50-52]}$. In addition to this, lifestyle-associated and environmental factors may also cause infertility ${ }^{[53]}$. A couple facing problems to have child should decide to move health care centers and agree to go with initial checkups. Involvement of both husband and wife in initial assessment and questioners enable them to pursue the exact investigation and nursing care. Such primary examination and history evaluation not only help to locate risk factors but also explore other hidden causes of infertility. Nurses provide space to the women to gather maximum information to explore infertility reasons ${ }^{[54-56]}$. Nurses are trained to initiate sensitive and private talks including sexually transmitted diseases and abortion with women's to analyze the optimum cause ${ }^{[57-58]}$. Such investigations may identify the need for specialist doctors and further physical examinations.

\subsection{Early pregnancy issues}

There has been a set of guidelines for nurse practitioners for the early pregnancy unit to must-have clinical coordination and leadership quality. Women's safety should be the ideal goal during early pregnancy circumstances ${ }^{[59]}$. Such skilled nursing practitioner not only helps in effective treatment but also lower down the hospital stay of patients. Basics of embryology revealed the release of oocytes from the ovary and captured by fallopian tubes ${ }^{[60]}$. Fertilization occurs in the ampulla of the fallopian tube which results in the formation of a zygote followed by several cell divisions to form morula and blastula stages. At $5^{\text {th }}$ day of fertilization, the blastocyst stage of the embryo moves forward in fallopian tubes and starts to implant in the uterus ${ }^{[61-62]}$. This is the time when blastocyst starts to produce a detectable amount of HCG (human 
chorionic gonadotropin) in urine. On the $20^{\text {th }}$ day, one can easily find the development of heart pulsation. Bleeding during this period is a time of concern and medical visit for women. They may feel intense pain, stress and be in a panic to investigate their concern about developing fetus ${ }^{[63]}$. Nurse practitioners try to investigate such cases by interacting with patients in terms of miscarriages. It may be a challenging perspective for nurse practitioners to provide the right guidance and counseling to the women patients suffering from bleeding and pain. Practitioners are suggested to confirm intrauterine pregnancy via transvaginal ultrasound ${ }^{[64-66]}$. As per the guidelines patient should be examined with full dignity and in the presence of a chaperone. There should not be any language barrier while doing the physical and hysteroscopy examination and a proper language translator should be provided. Early bleeding might be associated with miscarriage therefore it is recommended to evaluate thoroughly for the gynecological history of the patients ${ }^{[67-69]}$. Statistic's analysis suggests that out of four women one faces miscarriage issues. Such miscarriage incidences have been majorly seen during the initial 12 weeks of pregnancy.

\subsection{Abortion}

Millions of abortions are carried out each year globally due to several reasons. It has been seen that from the last decade the age profile of women's going for abortion changed a lot. Previously the women with abortion were majorly under the age of 25 but now a day's abortions cases observed with above $30^{\text {[70-72]. }}$ Ladies who are planning to undergo abortion required significant nursing care. Abortion is required to make lawful by taking the consent of a registered medical doctor. Generally, abortion is done if there's any death or permanent injuries associated with the risk to a pregnant lady. Recent studies have confirmed the significant role of nurses and midwives to handle pre-abortion cases ${ }^{[73,74]}$. During pre-abortion period, women need a positive environment, and should not feel alone. Such an environment allows women to disclose domestic violence, or sexual assault to further make sure that abortion is essential to conduct ${ }^{[75,76]}$. In several cases, it has been seen that women are determined for their decision to go with abortion, however, if they unsure then all the options should be discussed.

\subsection{Menopause}

Menopause is the condition when a women's menstrual cycle ends due to the natural aging process. At this stage, they will not be considered fertile as of loss of follicular activity and ovulation ${ }^{[77,78]}$. Women possessed six hundred thousand fertile oocytes at the time of puberty but the number decreased significantly during the natural aging process. At the age of 45 years, the majority of women's experiences irregularities in the menstrual cycle and eventually stops ovulation and entered in menopause phase ${ }^{[79]}$. The complex mechanisms of hormonal action are observed at the time of menopause. For instance, low secretion of estrogen, progesterone, testosterone, follicle-stimulating hormone (FSH), luteinizing hormone (LH) associated with loss of follicular activity ${ }^{[80-82]}$. In several countries around the $50^{\text {th }}$ of the year, women's entered menopause and lost their reproductive life. Women gradually face peri-menopause to postmenopause phases and required regular medical and nursing healthcare ${ }^{[83-84]}$. Nurses are specially trained to support and understand the signs of menopause in women. Nurses provide briefings to women's patients about psychological and medical treatment strategies such as hormonal therapies to overcome peri and postmenopause phases ${ }^{[85,86]}$. Surgical menopause is the term where ovaries are removed due to one or several reasons including fibrosis, or tumor. In such cases, symptoms of menopause are found to be very severe towards women's health.

\subsection{Sexual health of women}

Pleasant and negotiated sex can foster closeness in the relationship and build trust between the couple. It has been considered that satisfying sex life not only enhances fertility but also strengthens mental health. 
On the other hand, unhappy sex life may be responsible for stressful life ${ }^{[87-89]}$. Therefore, it has been essential to improving sexual life to enhance wellbeing in a cost-effective manner. Sexual health needs to be monitored to lower down the sexually transmitted infections, and unintentional pregnancies. The awareness about sexual health and reproductive life is essential to spread at health care and maternity centers. Nurses have been found to play an important role to provide confidential space to the women to share sensitive issues ${ }^{[90-92]}$. Patients should feel comfortable disclosing ongoing health problems. Nurses are encouraged to give person-centered care to women patients. Studies revealed that sexual health can enhance happiness in a patient's life. However, there should be a balance between sexual health and contraception methodology.

\subsection{Gynecologic oncology}

Cancer is unorganized growth of cells and considered to be one of the prime causes of mortality each year. Uncontrolled growths of tumors are found to show metastasis and spreading from one site to another. There have been a variety of cancer treatment strategies are available such as chemotherapy, radiotherapy, and surgical procedures ${ }^{[93-95]}$. Nurses are found to play an important role during cancer treatment of patients. Women who are facing gynecological cancer have to appear for examination in front of a multidisciplinary gynae medical team. At the time of cancer diagnosis, each patient is allocated a skilled nurse practitioner to look after for cancer care, in addition, to support emotionally ${ }^{[96-98]}$. Such trained nurse practitioners guide the patients towards their financial and psychological worries throughout the treatment journey. Nurses are provided with a set of questioners to explore the physical, spiritual, and social behaviors of the cancer patient to come up with promising cancer care oriented strategy. Such prior information at the time of diagnosis will not only speed up the cancer treatment efficacy but also strengthens patient's trust towards cancer therapies ${ }^{[99,100]}$. Nurse practitioners have to present the patient's report in multidisciplinary meetings and provides support to gynecology patients. Once treatment procedures of patients are completed, nurse practitioners provide a briefing on recurrence symptoms of the disease and guide them to supervise such signs.

\section{Conclusion}

Evidence suggested that women required regular counseling and health checkups to avoid serious gynecological disorders. Nurse practitioner guidance may provide an impressive roadmap to the girls to overcome the prickly journey from menarche to menopause and later on. Previous studies strengthen the role of nurses to educate women patients about the phases and consequences of disease and possible management of therapeutic strategies. Nurses are found to play a critical role before and after the patent surgery too. In the present scenario, the scarcity of medical staff in rural areas may be fulfilled up to a certain extent by trained and skilled nurse practitioners. Such gynecological specialist nurses can provide health information to women's patients as per NICE guidelines. Therefore, it is worthy to make nurses an integral part of clinical settings.

\section{Disclosure statement}

The author declares no conflict of interest.

\section{References}

[1] Landeen, J., Carr, D., Culver, K., Martin, L., Matthew-Maich, N., Noesgaard, C. and Beney-Gadsby, L., 2016. The impact of curricular changes on BSCN students' clinical learning outcomes. Nurse Education in Practice, 21, pp.51-58. 
[2] Zabalegui, A. and Cabrera, E., 2009. New nursing education structure in Spain. Nurse education today, 29(5), pp.500-504.

[3] Oyetunde, M.O. and Oluwafunke, K.I., 2015. Professional development and career pathway in nursing. Int J Sci, 4(6), pp.92-104.

[4] Noone, J., Carmichael, J., Carmichael, R.W. and Chiba, S.N., 2007. An organized pre-entry pathway to prepare a diverse nursing workforce. Journal of Nursing Education, 46(6), pp.287-291.

[5] Weinberg, A. and Creed, F., 2000. Stress and psychiatric disorder in healthcare professionals and hospital staff. the Lancet, 355(9203), pp.533-537.

[6] Zavala, M.O.Q., Klinj, T.P. and Carrillo, K.L.S., 2016. Quality of life in the workplace for nursing staff at public healthcare institutions. Revista latino-americana de enfermagem, 24.

[7] Farr, M. and Cressey, P., 2015. Understanding staff perspectives of quality in practice in healthcare. BMC health services research, 15(1), pp.1-11.

[8] Davis, J.D., 2002. Comparison of faculty, peer, self, and nurse assessment of obstetrics and gynecology residents. Obstetrics \& Gynecology, 99(4), pp.647-651.

[9] Brady, M.A., Carroll, A.W., Cheang, K.I., Straight, C. and Chelmow, D., 2015. Sequential compression device compliance in postoperative obstetrics and gynecology patients. Obstetrics \& Gynecology, 125(1), pp.19-25.

[10] Arora, V., Philp, S., Nattress, K., Pather, S., Dalrymple, C., Atkinson, K., Smirnova, S., Cotterell, S. and Carter, J., 2010. Patient satisfaction with inpatient care provided by the Sydney Gynecological Oncology Group. Patient related outcome measures, 1, p.179.

[11] Cook, O., McIntyre, M. and Recoche, K., 2015. Exploration of the role of specialist nurses in the care of women with gynaecological cancer: a systematic review. Journal of clinical nursing, 24(56), pp.683-695.

[12] Koutsopoulou, S., Papathanassoglou, E.D., Katapodi, M.C. and Patiraki, E.I., 2010. A critical review of the evidence for nurses as information providers to cancer patients. Journal of Clinical Nursing, 19(5-6), pp.749-765.

[13] Thomas, S.L. and Ellertson, C., 2000. Nuisance or natural and healthy: should monthly menstruation be optional for women?. The Lancet, 355(9207), pp.922-924.

[14] Roberts, T.A., Goldenberg, J.L., Power, C. and Pyszczynski, T., 2002. "Feminine protection": The effects of menstruation on attitudes towards women. Psychology of Women Quarterly, 26(2), pp.131-139.

[15] Singh, A.J., 2006. Place of menstruation in the reproductive lives of women of rural North India. Indian Journal of Community Medicine, 31(1), p.10.

[16] Kaunitz, A.M., 2000. Menstruation: choosing whether... and when. Contraception, 62(6), pp.277284.

[17] Wojtys, E.M., Huston, L.J., Boynton, M.D., Spindler, K.P. and Lindenfeld, T.N., 2002. The effect of the menstrual cycle on anterior cruciate ligament injuries in women as determined by hormone levels. The American journal of sports medicine, 30(2), pp.182-188.

[18] MacGregor, E.A., 1997. Menstruation, sex hormones, and migraine. Neurologic clinics, 15(1), pp.125-141.

[19] Feinberg, D.R., Jones, B.C., Smith, M.L., Moore, F.R., DeBruine, L.M., Cornwell, R.E., Hillier, S.G. and Perrett, D.I., 2006. Menstrual cycle, trait estrogen level, and masculinity preferences in the human voice. Hormones and behavior, 49(2), pp.215-222.

[20] Roney, J.R., 2018. Hormonal mechanisms and the optimal use of luteinizing hormone tests in human menstrual cycle research. Hormones and behavior, 106, pp.A7-A9. 
[21] Mamo, L. and Fosket, J.R., 2009. Scripting the body: Pharmaceuticals and the (re) making of menstruation. Signs: Journal of Women in Culture and Society, 34(4), pp.925-949.

[22] Cronje, H.S. and Kritzinger, I.E., 1991. Menstruation: symptoms, management and attitudes in university students. International Journal of Gynecology \& Obstetrics, 35(2), pp.147-150.

[23] Rościszewska, D., Buntner, B., Guz, I. and Zawisza, L., 1986. Ovarian hormones, anticonvulsant drugs, and seizures during the menstrual cycle in women with epilepsy. Journal of Neurology, Neurosurgery \& Psychiatry, 49(1), pp.47-51.

[24] Gissmann, L., Boshart, M., Dürst, M., Ikenberg, H., Wagner, D. and Zur Hausen, H., 1984. Presence of human papillomavirus in genital tumors. Journal of Investigative Dermatology, 83(1), pp.S26S28.

[25] Halpert, R.I.C.H.A.R.D., Fruchter, R.G., Sedlis, A.L.E.X.A.N.D.E.R., Butt, K.H.A.L.I.D., Boyce, J.G. and Sillman, F.H., 1986. Human papillomavirus and lower genital neoplasia in renal transplant patients. Obstetrics and Gynecology, 68(2), pp.251-258.

[26] Sichero, L., Giuliano, A.R. and Villa, L.L., 2019. Human papillomavirus and genital disease in men: what we have learned from the HIM study. Acta cytologica, 63(2), pp.109-117.

[27] Roden, R.B. and Stern, P.L., 2018. Opportunities and challenges for human papillomavirus vaccination in cancer. Nature Reviews Cancer, 18(4), p.240.

[28] Taberna, M., Mena, M., Pavón, M.A., Alemany, L., Gillison, M.L. and Mesía, R., 2017. Human papillomavirus-related oropharyngeal cancer. Annals of Oncology, 28(10), pp.2386-2398.

[29] de Sanjose, S., Brotons, M. and Pavon, M.A., 2018. The natural history of human papillomavirus infection. Best practice \& research Clinical obstetrics \& gynaecology, 47, pp.2-13.

[30] Yete, S., D’Souza, W. and Saranath, D., 2018. High-risk human papillomavirus in oral cancer: clinical implications. Oncology, 94(3), pp.133-141.

[31] Patel, H., Austin-Smith, K., Sherman, S.M., Tincello, D. and Moss, E.L., 2017. Knowledge, attitudes and awareness of the human papillomavirus amongst primary care practice nurses: an evaluation of current training in England. Journal of Public Health, 39(3), pp.601-608.

[32] Pu, J., He, M., Pu, Y., Liu, Z., Le, L., Wang, H. and Du, X., 2021. Knowledge about Human Papillomavirus and Cervical Cancer Prevention among Intern Nurses. Asia-Pacific Journal of Oncology Nursing, 8(1), p.46.

[33] Torabizadeh, C., Nick, N., Vizeshfar, F., Jamalimoghadam, N. and Bagheri, S., 2020. Effectiveness of an Educational Intervention to Increase Human Papillomavirus Knowledge and Attitude in Staff and Nursing Students. Journal of Community Health Nursing, 37(4), pp.214-221.

[34] Bayramoğlu Tepe, N. and Ozcorekci, O., 2020. Knowledge about the human papillomavirus among high school and university students a comprehensive questionnaire study from Southeast Turkey. Journal of Obstetrics and Gynaecology Research, 46(6), pp.907-916.

[35] Tschann, P., Lechner, D., Feurstein, B., Abendstein, B., Dertinger, S., Bösl, A., Vitlarov, N., Offner, F. and Königsrainer, I., 2020. Diagnostically challenging human papillomavirus-associated primary squamous cell carcinoma of the rectum with metastasis in both ovaries: a case report. Journal of medical case reports, 14(1), pp.1-7.

[36] Barendse, M.E., Cosme, D., Flournoy, J.C., Vijayakumar, N., Cheng, T.W., Allen, N.B. and Pfeifer, J.H., 2020. Neural correlates of self-evaluation in relation to age and pubertal development in early adolescent girls. Developmental Cognitive Neuroscience, 44, p.100799.

[37] Laube, C., van den Bos, W. and Fandakova, Y., 2020. The relationship between pubertal hormones and brain plasticity: Implications for cognitive training in adolescence. Developmental cognitive neuroscience, 42, p.100753. 
[38] Simmons, R.G. ed., 2017. Moving into adolescence: The impact of pubertal change and school context. Routledge.

[39] Sawyer, S.M., Azzopardi, P.S., Wickremarathne, D. and Patton, G.C., 2018. The age of adolescence. The Lancet Child \& Adolescent Health, 2(3), pp.223-228.

[40] Emmanuel, M. and Bokor, B.R., 2017. Tanner stages.

[41] Ohlsson, C., Bygdell, M., Nethander, M. and Kindblom, J.M., 2020. Early puberty and risk for type 2 diabetes in men. Diabetologia, pp.1-10.

[42] Genovesi, S., Orlando, A., Rebora, P., Giussani, M., Antolini, L., Nava, E., Parati, G. and Valsecchi, M.G., 2018. Effects of Lifestyle Modifications on Elevated Blood Pressure and Excess Weight in a Population of Italian Children and Adolescents. American journal of hypertension, 31(10), pp.11471155.

[43] Abdolahian, S., Tehrani, F.R., Amiri, M., Ghodsi, D., Yarandi, R.B., Jafari, M., Majd, H.A. and Nahidi, F., 2020. Effect of lifestyle modifications on anthropometric, clinical, and biochemical parameters in adolescent girls with polycystic ovary syndrome: a systematic review and metaanalysis. BMC endocrine disorders, 20, pp.1-17.

[44] Mohamadi, S., Garkaz, O., Mousavi, S.A., Keramat, A., Goli, S. and Motaghi, Z., 2021. The Effect of Motivational Interview on Puberty Knowledge and Practice among Adolescent Girls. Nursing and Midwifery Studies, 10(1), p.13.

[45] Mokhtari Nouri, J., Jalali, M., Parandeh, A. and Javadi, M., 2019. The Effectiveness of Education Based on Health Belief Model on Promoting Preventive Behaviors of Mothers from Girls' Early Puberty. Journal of Nursing Education, 8(2), pp.37-43.

[46] Deatsman, S., Vasilopoulos, T. and Rhoton-Vlasak, A., 2016. Age and fertility: a study on patient awareness. JBRA assisted reproduction, 20(3), p.99.

[47] Lucas, A.F., Gemechu, D.B., Du Plessis, S.S. and Aboua, Y.G., 2021. Fertility and pregnancy outcome among women undergoing assisted reproductive technology treatment in Windhoek, Namibia. Journal of Assisted Reproduction and Genetics, pp.1-9.

[48] Song, Y. and Li, R., 2021. Effects of Environment and Lifestyle Factors on Anovulatory Disorder. In Environment and Female Reproductive Health (pp. 113-136). Springer, Singapore.

[49] Kermack, A.J., 2021. Lifestyle factors and women's health. In A Prescription for Healthy Living (pp. 211-224). Academic Press.

[50] Poppe, K.G., 2021. Management of endocrine disease: Thyroid and Female Infertility: More Questions than Answers?!. European Journal of Endocrinology, 1(aop).

[51] Saleem, S., Shaheen, A., Jabeen, A. and Mahmood, Z., 2021. Psychosocial Issues in Women with Primary Infertility: A Psychometric Study. Annals of King Edward Medical University, 27(1).

[52] Swift, A., Reis, P. and Swanson, M., 2021. Infertility Stress, Cortisol, Coping, and Quality of Life in US Women Who Undergo Infertility Treatments. Journal of Obstetric, Gynecologic \& Neonatal Nursing.

[53] Emokpae, M.A. and Brown, S.I., 2021. Effects of lifestyle factors on fertility: practical recommendations for modification. Reproduction and Fertility, 2(1), pp.R13-R26.

[54] Elsous, A., El-Kass, S.D.A., Salama, A., Radwan, M., Abo-Eid, S. and Baloushah, S., 2021. Depression among infertile women in Gaza Strip: symptom severity and predictors. Depression research and treatment, 2021.

[55] Grube, T., 2020. Management of Involuntary Childlessness in Couples With Infertility. Journal of Obstetric, Gynecologic \& Neonatal Nursing, 49(6), pp.S4-S5.

[56] Ingrit, B.L., 2020. Women's Experience In Using “Complementary Nursing On Infertility”. Saintika Medika: Jurnal Ilmu Kesehatan dan Kedokteran Keluarga, 16(1), pp.41-49. 
[57] Norton, W. and Wright, E., 2020. Barriers and Facilitators to Fertility-Related Discussions with Teenagers and Young Adults with Cancer: Nurses' Experiences. Journal of adolescent and young adult oncology, 9(4), pp.481-489.

[58] Taksande, A.V., Taksande, V. and Patil, M., 2020. Case Report on Primary Infertility. Indian Journal of Forensic Medicine \& Toxicology, 14(4).

[59] Nagle, A., Srinivasulu, S., Maldonado, L. and deFiebre, G., 2021. Provision of early pregnancy loss care in New York federally qualified health centers. The Journal of the American Board of Family Medicine, 34(1), pp.238-242.

[60] Hirohashi, N. and Yanagimachi, R., 2018. Sperm acrosome reaction: its site and role in fertilization. Biology of reproduction, 99(1), pp.127-133.

[61] Lindström, J., 1999. Early development and fitness in birds and mammals. Trends in Ecology \& Evolution, 14(9), pp.343-348.

[62] Eppig, J.J., 2001. Oocyte control of ovarian follicular development and function in mammals. Reproduction, 122(6), pp.829-838.

[63] Yang, P., Wang, Y., Wu, Z., Pan, N., Yan, L. and Ma, C., 2019. Risk of miscarriage in women with endometriosis undergoing IVF fresh cycles: a retrospective cohort study. Reproductive Biology and Endocrinology, 17(1), pp.1-9.

[64] Edwards, S., Birks, M., Chapman, Y. and Yates, K., 2018. Bringing together the 'threads of care'in possible miscarriage for women, their partners and nurses in non-metropolitan EDs. Collegian, 25(3), pp.293-301.

[65] Emond, T., de Montigny, F. and Guillaumie, L., 2019. Exploring the needs of parents who experience miscarriage in the emergency department: A qualitative study with parents and nurses. Journal of clinical nursing, 28(9-10), pp.1952-1965.

[66] Griffin, G., Ngulube, M., Farrell, V. and Hauck, Y.L., 2020. Caring for women through early pregnancy loss: Exploring nurses' experiences of care. Collegian.

[67] Moradinazar, M., Najafi, F., Nazar, Z.M., Hamzeh, B., Pasdar, Y. and Shakiba, E., 2020. Lifetime Prevalence of Abortion and Risk Factors in Women: Evidence from a Cohort Study. Journal of pregnancy, 2020.

[68] Cavalcante, M.B., Sarno, M., Peixoto, A.B., Araujo Junior, E. and Barini, R., 2019. Obesity and recurrent miscarriage: A systematic review and meta-analysis. Journal of Obstetrics and Gynaecology Research, 45(1), pp.30-38.

[69] Woolner, A.M., Nagdeve, P., Raja, E.A., Bhattacharya, S. and Bhattacharya, S., 2020. Family history and risk of miscarriage: A systematic review and meta-analysis of observational studies. Acta Obstetricia et Gynecologica Scandinavica, 99(12), pp.1584-1594.

[70] Sultana, A., 2020. Induced abortion: Rural Women's Escape against Unintended Pregnancies. Pakistan Vision, 21(1), p.466.

[71] Bell, S.O., Omoluabi, E., OlaOlorun, F., Shankar, M. and Moreau, C., 2020. Inequities in the incidence and safety of abortion in Nigeria. BMJ global health, 5(1), p.e001814.

[72] Mekonnen, A. and Awoke, Z., 2020. Assessment of Knowledge, Attitude and Practice Women of Reproductive Age Group Towards Abortion Care at Gambella Health Facilities, South West of Ethiopia. International Journal of Biomedical Engineering and Clinical Science, 6(2), p.29.

[73] Mainey, L., O’Mullan, C., Reid-Searl, K., Taylor, A. and Baird, K., 2020. The role of nurses and midwives in the provision of abortion care: A scoping review. Journal of clinical nursing, 29(9-10), pp.1513-1526.

[74] Hajri, S. and Belhadj, H., 2020. The role of midwives in first-trimester abortion care: A 40-year experience in Tunisia. International Journal of Gynecology \& Obstetrics, 150, pp.43-48. 
[75] Haddad, S., Martin-Marchand, L., Lafaysse, M. and Saurel-Cubizolles, M.J., 2021. Repeat induced abortion and adverse childhood experiences in Aquitaine, France: a cross-sectional survey. The European Journal of Contraception \& Reproductive Health Care, 26(1), pp.29-35.

[76] Drew, L.B., Mittal, M., Thoma, M.E., Harper, C.C. and Steinberg, J.R., 2020. Intimate partner violence and effectiveness level of contraceptive selection post-abortion. Journal of Women's Health, 29(9), pp.1226-1233.

[77] Santoro, N., Roeca, C., Peters, B.A. and Neal-Perry, G., 2021. The Menopause Transition: Signs, Symptoms, and Management Options. The Journal of Clinical Endocrinology \& Metabolism, 106(1), pp.1-15.

[78] Gordon, J.L., Sander, B., Eisenlohr-Moul, T.A. and Tottenham, L.S., 2020. Mood sensitivity to estradiol predicts depressive symptoms in the menopause transition. Psychological medicine, pp.19.

[79] Maki, P.M. and Thurston, R.C., 2020. Menopause and Brain Health: Hormonal Changes Are Only Part of the Story. Frontiers in Neurology, 11, p.1074.

[80] Santoro, N., El Khoudary, S.R., Nasr, A., Gold, E.B., Greendale, G., McConnell, D., Neal-Perry, G., Pavlovic, J., Derby, C. and Crawford, S., 2020. Daily luteal serum and urinary hormone profiles in the menopause transition: Study of Women's Health Across the Nation. Menopause, 27(2), pp.127133.

[81] Cortés, Y.I., Marginean, V. and Berry, D., 2020. Physiologic and psychosocial changes of the menopause transition in US Latinas: a narrative review. Climacteric, pp.1-15.

[82] Marjoribanks, J., Farquhar, C., Roberts, H. and Lethaby, A., 2012. Long term hormone therapy for perimenopausal and postmenopausal women. Cochrane Database of Systematic Reviews, (7).

[83] Macdonald, H.M., New, S.A., Campbell, M.K. and Reid, D.M., 2005. Influence of weight and weight change on bone loss in perimenopausal and early postmenopausal Scottish women. Osteoporosis international, 16(2), pp.163-171.

[84] Pinkerton, J.V., Conner, E.A. and Kaunitz, A.M., 2019. Management of menopause and the role For hormone therapy. Clinical obstetrics and gynecology, 62(4), pp.677-686.

[85] Berterö, C., 2003. What do women think about menopause? A qualitative study of women's expectations, apprehensions and knowledge about the climacteric period. International Nursing Review, 50(2), pp.109-118.

[86] Mahadeen, A.I., Halabi, J.O. and Callister, L.C., 2008. Menopause: a qualitative study of Jordanian women's perceptions. International nursing review, 55(4), pp.427-433.

[87] Heiman, J.R., Long, J.S., Smith, S.N., Fisher, W.A., Sand, M.S. and Rosen, R.C., 2011. Sexual satisfaction and relationship happiness in midlife and older couples in five countries. Archives of sexual behavior, 40(4), pp.741-753.

[88] Dogan, T., Tugut, N. and Golbasi, Z., 2013. The relationship between sexual quality of life, happiness, and satisfaction with life in married Turkish women. Sexuality and Disability, 31(3), pp.239-247.

[89] Rahmani, A., Khoei, E.M. and Gholi, L.A., 2009. Sexual satisfaction and its relation to marital happiness in Iranians. Iranian Journal of Public Health, pp.77-82.

[90] Nakopoulou, E., Papaharitou, S. and Hatzichristou, D., 2009. Patients' sexual health: a qualitative research approach on Greek nurses' perceptions. The Journal of Sexual Medicine, 6(8), pp.21242132.

[91] Saunamäki, N. and Engström, M., 2014. Registered nurses' reflections on discussing sexuality with patients: responsibilities, doubts and fears. Journal of Clinical Nursing, 23(3-4), pp.531-540. 
[92] Gott, M., Galena, E., Hinchliff, S. and Elford, H., 2004. “Opening a can of worms": GP and practice nurse barriers to talking about sexual health in primary care. Family practice, 21(5), pp.528-536.

[93] Tuli, H.S., Aggarwal, V., Kaur, J., Aggarwal, D., Parashar, G., Parashar, N.C., Tuorkey, M., Kaur, G., Savla, R., Sak, K. and Kumar, M., 2020. Baicalein: A metabolite with promising antineoplastic activity. Life Sciences, p.118183.

[94] Tuli, H.S., Mittal, S., Loka, M., Aggarwal, V., Aggarwal, D., Masurkar, A., Kaur, G., Varol, M., Sak, K., Kumar, M. and Sethi, G., 2021. Deguelin targets multiple oncogenic signaling pathways to combat human malignancies. Pharmacological Research, p.105487.

[95] Aggarwal, V., Tuli, H.S., Thakral, F., Singhal, P., Aggarwal, D., Srivastava, S., Pandey, A., Sak, K., Varol, M., Khan, M.A. and Sethi, G., 2020. Molecular mechanisms of action of hesperidin in cancer: Recent trends and advancements. Experimental Biology and Medicine, 245(5), pp.486-497.

[96] Philp, S., Carter, J., Barnett, C., D’Abrew, N., Pather, S. and White, K., 2015. Patients' perspectives of fast-track surgery and the role of the fast-track clinical nurse consultant in gynecological oncology. Holistic nursing practice, 29(3), pp.158-166.

[97] Shi, Y., Cai, J., Wu, Z., Jiang, L., Xiong, G., Gan, X. and Wang, X., 2020. Effects of a nurse-led positive psychology intervention on sexual function, depression and subjective well-being in postoperative patients with early-stage cervical cancer: A randomized controlled trial. International Journal of Nursing Studies, 111, p.103768.

[98] Alotaibi, T. and Al Anizi, C.A., 2020. The impact of advanced nurse practitioner (ANP) role on adult patients with cancer: A quantitative systematic review. Applied Nursing Research, p.151370.

[99] Chen, Q., Mariano, E.R. and Lu, A.C., 2021. Enhanced recovery pathways and patient-reported outcome measures in gynaecological oncology. Anaesthesia, 76, pp.131-138.

[100] Abdelhafez, A.M., Ibrahim, N., Aref, A.F. and Abou-Taleb, H., 2020. Outcomes of Routine perioperative Nursing Care for Women Undergoing Gynecologic Cancer surgeries. Assiut Scientific Nursing Journal, 8(23), pp.182-193. 